ISSN 1112-9867

\title{
AN INFORMATION MODEL OF A CENTRALIZED ADMISSION CAMPAIGN IN RUSSIAN HIGHER EDUCATION INSTITUTIONS
}

\author{
A. I. Pykhtin", O. V. Ovchinkin \\ Southwest State University 305040, Kursk, st.50 years of October, 94
}

Published online: 08 August 2017

\begin{abstract}
The aim of the work is to structure individual application environments of the information model of a centralized admission campaign in higher education institutions in Russia by modifying the corresponding structure of the Federal information system supporting state final examination and admission procedures. , The IDEF1X modeling methodology was used as research tool. The main result of the work is the formation of such information model subject areas as Educational programs, Entrance exams, Applicant's Priorities and Physical persons. Practical implementation of this model will reduce the costs of universities to support their own information systems, strengthen controls over the compliance with Russian legislation requirements in the field of higher education, ensure the most open and transparent way of applicants' competitive selection. Identified are the blocks of the model of the Federal information system that have already been implemented but require certain modification. The information model can be used in other countries with similar state final examination and state information systems.
\end{abstract}

Keywords: admission to universities, information model, applicant.

\section{INTRODUCTION}

In modern situation higher education institutions (universities) have to meet very strict and sometimes very ambiguous requirements to the admission procedures. These requirements mainly deal with information openness, protection of personal data, data export to Federal information systems like FIS GIA (State Final Examination and Higher School Admission

Author Correspondence, e-mail: author@gmail.com

doi: $\underline{\text { http://dx.doi.org/10.4314/jfas.v9i2s.66 }}$ 
Information System), FRDO (Federal Registrar of Education Certificates), gzgu.ru, etc., and presenting extended reports to governmental and municipal authorities. Such processes can hardly be well organized without a specialized information system. Depending on specific admission requirements and individual university features national higher education institutions either develop their own software products (for example [1,2]) or use external products that are usually made in cooperation with other educational institutions (examples are 1C: Universitet. Galaktika Upravleniya Vuzom, TANDEM.Universitet and others).

According to the Federal portal Russian Education today Russia has over 2,600 higher education institutions (including branches). Each of them should continuously communicate with the said information systems either by means of external soft or by in-house developed products. As a conservative estimate annual soft development expenditures of a university are minimum 100000 rubles, which may equal at least 260 million rubles on a nation-wide scale. It is natural that under such conditions the issue of resource saving has become very important.

At present there is a growing competition for high school graduates among the universities, which is largely caused by the current critical demographic situation, by cutting down the number of inefficient educational institutions following the policy that has recently been pursued by the Ministry of Education and Science of the Russian Federation, by the formation of various ratings and admission procedure supervisory monitoring. The uniformity of university admission regulations opens prospect for the organization of admission campaigns within the framework of all-Russian uniform computer program system [3, 4]. This system can be a modified version of existing Federal information system that supports the State final examination and university admission system (hereon after referred to as SFE\&UA). Today SFE\&UA system is storing and processing the copy data received from university information systems. The data in the form of complex XML-packages is transferred to SFE\&UA system from university computer systems automatically or manually (if the number of applicants does not exceed 500 persons per year). Let us discuss the use of SFE\&UA system not as a supervision means, but rather as the main admission campaign management tool. This topic was brought up in [3], while the concept of admission centralization nationwide or on a regional level was discussed in [5]. It should be noted that admission campaign can be made centralized not only in Russia, but also abroad in the countries with similar state high school final examination systems and relative state information systems, for example, in China [6] or Kirgizia [7]. 


\section{RESEARCH METHODS}

The research method is IDEF1 (integration definition for information modeling) technique that is used to make information models and is able to represent the information structure needed to support the information system functions. Having applied this methodology we have singled out already existing entities and relations that have been implemented in SFE\&UA system and the entities to be developed. The considered information model fragments are built on the basis of IDEF0- the model of Russian university admission campaign [4].

\section{RESULTS AND DISCUSSION}

The core of any computer information system is formed by a database that should be able to store structured information about physical persons, such as applicants, students, employees, etc. Initial structure of a database is usually represented by IDEF1X information model.

In order to organize the admission to higher education institutions in Russia under a unified system it is necessary to ensure the possibility of storing information on all available educational programs, on the availability of vacant places in relation to different admission terms (Fig.1), on the set of admission tests and trials and minimal threshold scores (Fig. 2) for each educational institution within the framework of each admission campaign.

This possibility has already been provided for by SFE\&UA system in which each package of admission terms is called Competition Group that comprises the following elements: master key which is the competition identifier that is unique for a given institution; and the identifiers of the educational institution, admission campaign, education level (degree), financing source, form of studies, fields of studies and competition name. The Competition has subjugated entities containing the information about the curricula, availability of places, employersponsored programs, exclusive rights and admission tests.

It should be noted that SFE\&UA system is characterized by thoroughly elaborated approach to storing information on the changeability of admission tests depending on the university and exclusive rights granted to the winners of important dedicated competitions and contests among high school graduates. The corresponding information model entities can be left as designed. 


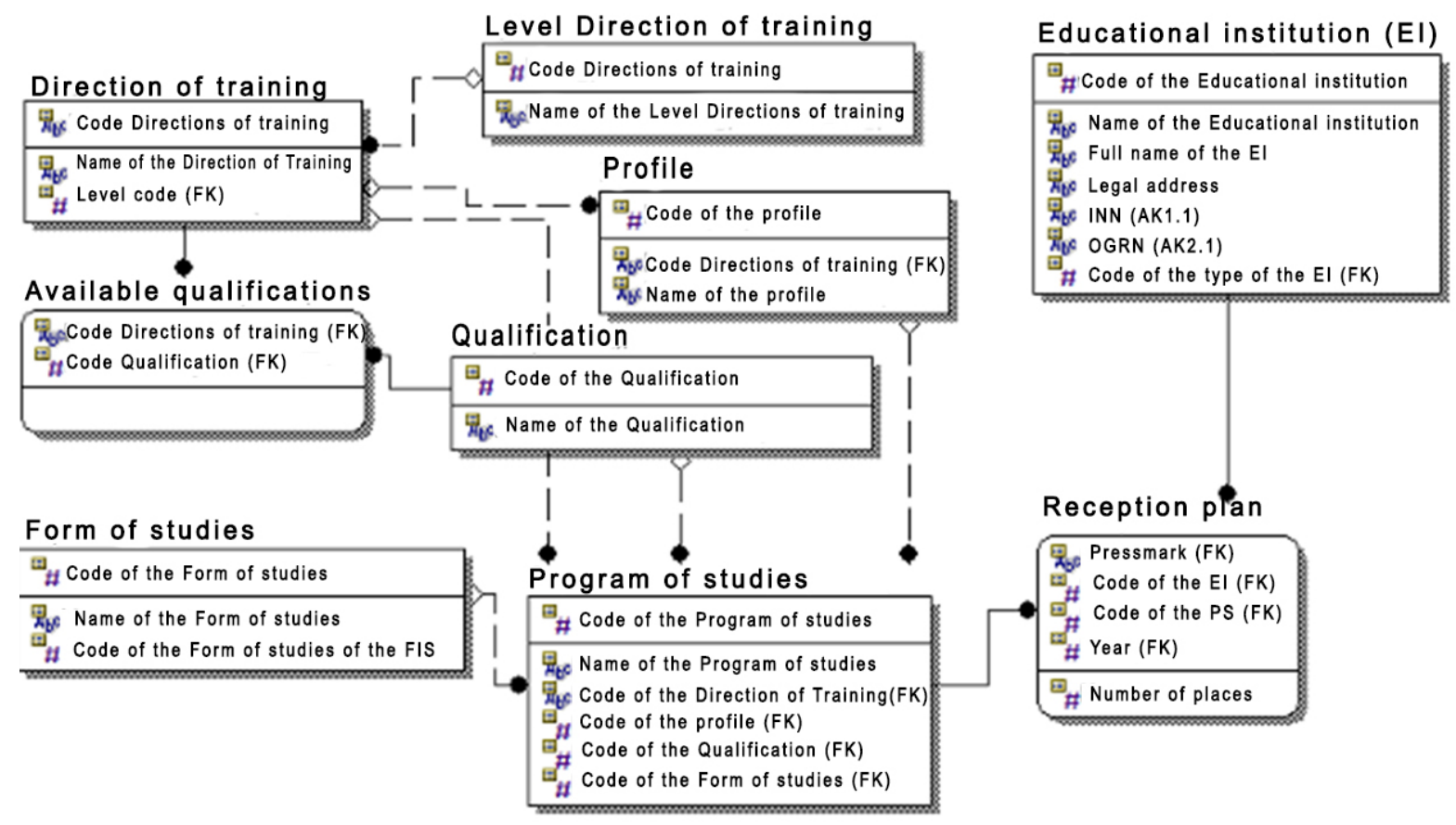

Fig.1. Application environment Curricula of IDEF1X-model

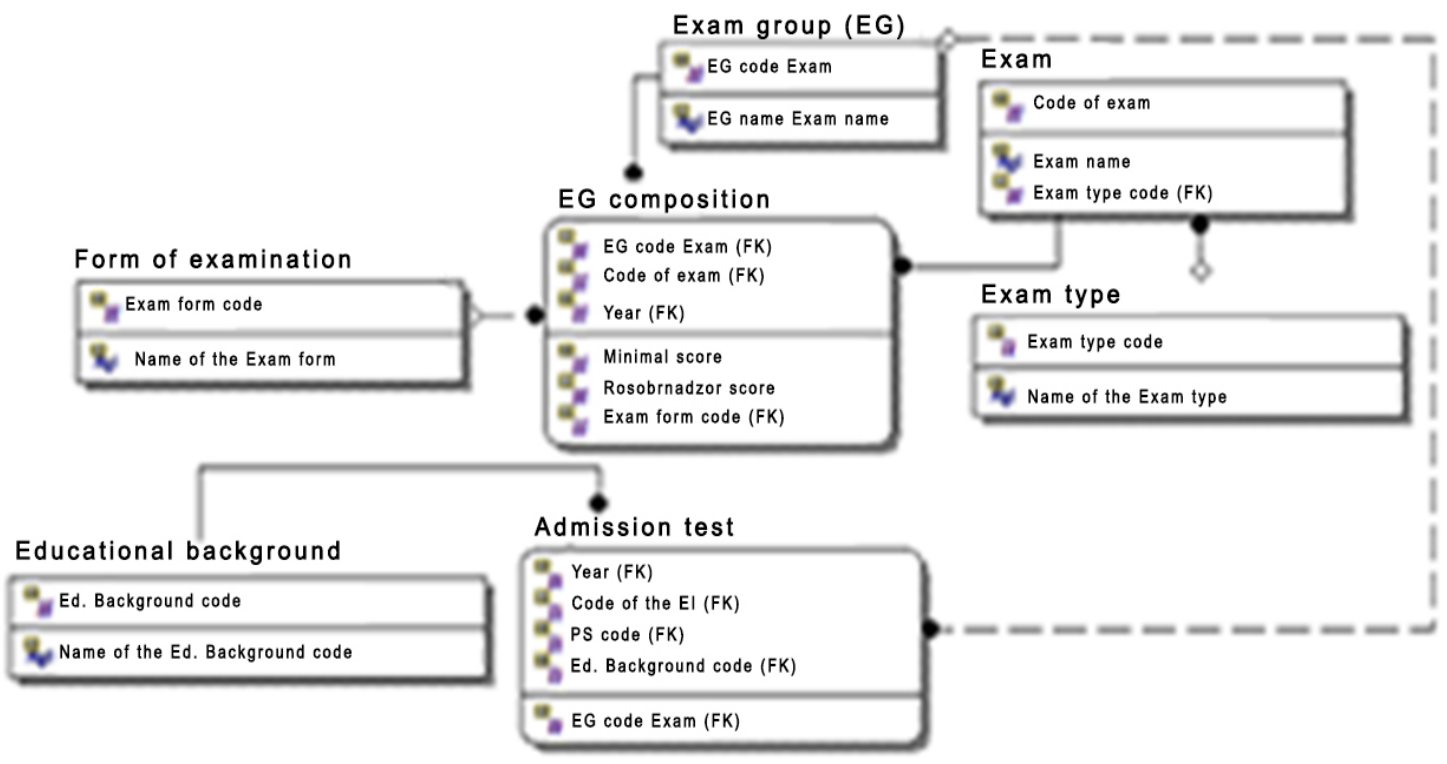

Fig.2. Application environment Admission tests of IDEF1X-model

As when using the all-Russian unified database the applicant should indicate not only selected specialties (fields of study) ranged according to his/her individual preferences with clearly identified admission terms (with or without admission tests, within a quota limit, supported by the employee's sponsorship, on general terms, etc.), the form of studies and education 
background, but also the educational institutions s/he would like to enter, the relevant entities are to be modified in IDEF1X- model. By modifying the entity we'll be able to track down the filing of applications to up to five institutions. The proposed fragment of IDEF1X-model is shown in Fig. 3. SFE\&UA system has a similar entity that is called Application, however, educational institutions make data entries independently from each other and cannot control their common applicants.

As for physical persons the data to be stored includes the full name, gender, date and place of birth, ID document information, address, phone number (-s) and e-mail address (-es). In order to work with the applicant in future there is also a need to have information about his/her close relatives, family status, eligibility for military service, etc.

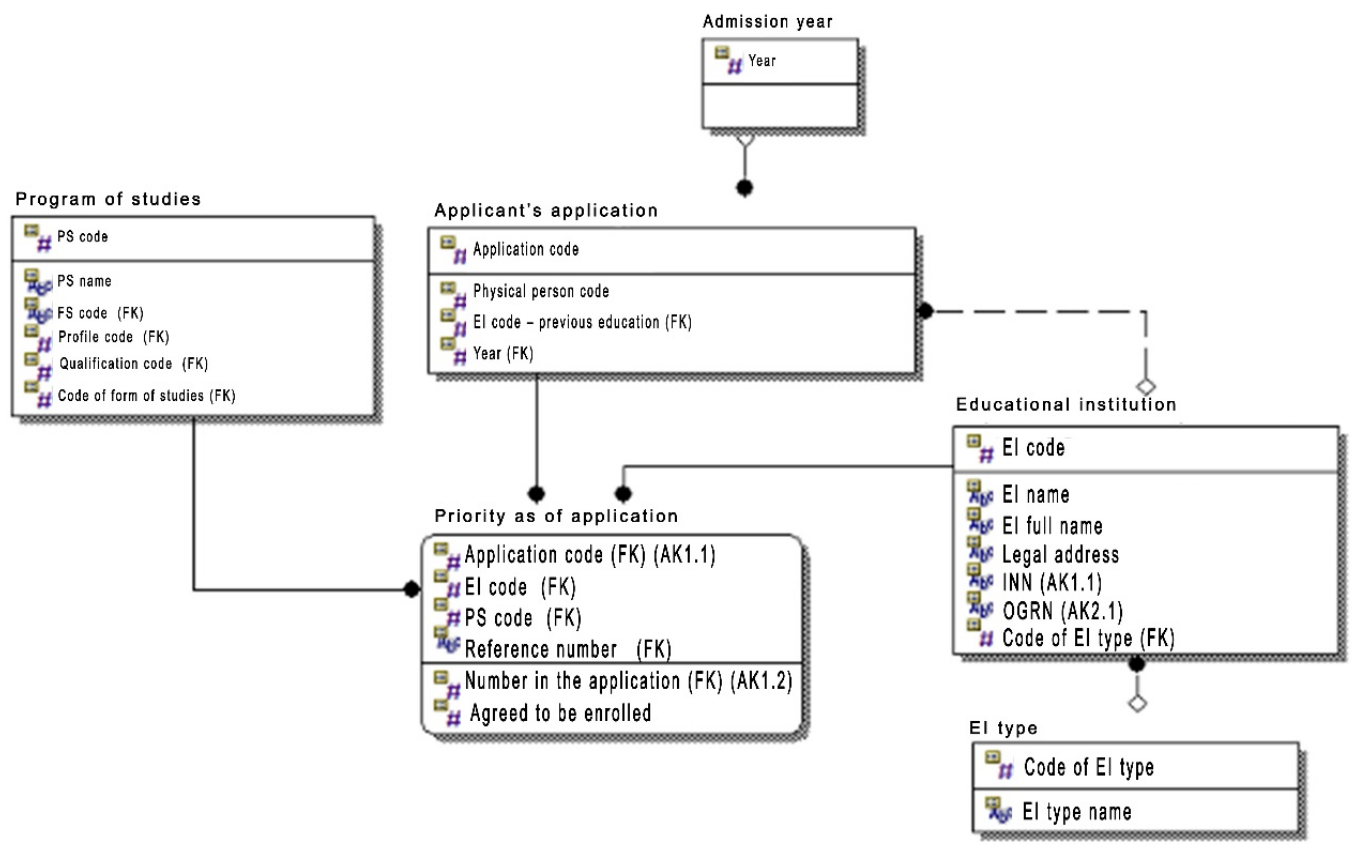

Fig.3. Application environment Applicant's priorities of IDEF1X-model

To find a master key of the entity Physical person is a serious challenge. An artificial numerical or symbol code can be used as the key attribute, however, secondary keys should also be chosen in order to conform with the principle of non-redundancy of the information on a physical person. The combination of the fields Name, Middle name (-s) (patronymic) and Family name cannot be a secondary key because the cases of namesakes are not unusual. The field Date of birth added to the key can solve the problem to a certain extent, though the coincidence of four attributes is quite probable. The combination of such attributes as the $I D$ document unique series and ID document unique number can identify a physical person 
exactly, but one and the same physical person may have different ID documents certifying the personality and citizenship, that is why the entity Document is represented by a separate table in the database (one physical person may have one or several matching ID documents). Thus there is a need in soft-based control of ID data reduplication. It may be applicable to supplement the database with the tables containing the lists of the most common names, patronymics and family names in order to enable index search so that to reduce the number of spelling mistakes made in personal data entries. Such typical mistakes include extra spacebar spaces, inadvertent switch to another keyboard format or a wrong letter case. In SFE\&UA system the problem of unambiguous identification of a physical person has not been solved yet; it admits data redundancy both within one institution and among several institutions. Nevertheless, SFE\&UA executes cross checks by passport data, for example, it is able to control whether the applicant has failed to meet the requirement limiting the number of educational institutions s/he may apply to, or controls the fact of dual matriculation in different institutions with budget-funded places.

The possibility to change the values of some attributes in time and the need to track such changes presents another problem. For example, it is necessary to keep the history of a student's name changes in order to manage in-house student body documents appropriately. The proposed fragment of IDEF1X-model used to describe physical person data is shown in Fig.4. So far SFE\&UA system makes no provisions for storing the personal data histories; the only one option is to store the information about the applicant's previous passport (-s) and earlier name(-s), which is needed to check the information on the applicant's State Final Examination results.

An important issue is to meet the requirements of the RF Federal Act On Personal Data of July 27, 2006, N 152-FZ. The idea is to take technical and organizational measures to ensure information protection with differentiating the levels of access to personal data depending on the authority of data processing operators both on the entry level and on entry attribute levels. Some contradictions are related with the agreement of a physical person about personal data processing, which is registered in the information system. For example, national regulations demand that public should have an unrestricted access to the lists of applicants with their State Final Examination scores and entrance test results that are to be published in media including university WEB-sites. SFE\&UA system advantage is its functioning within a protected corporate system of data transfer of the Federal Budgetary Institution Federal Test Center, which ensures full compliance with personal data protection legal requirements. 


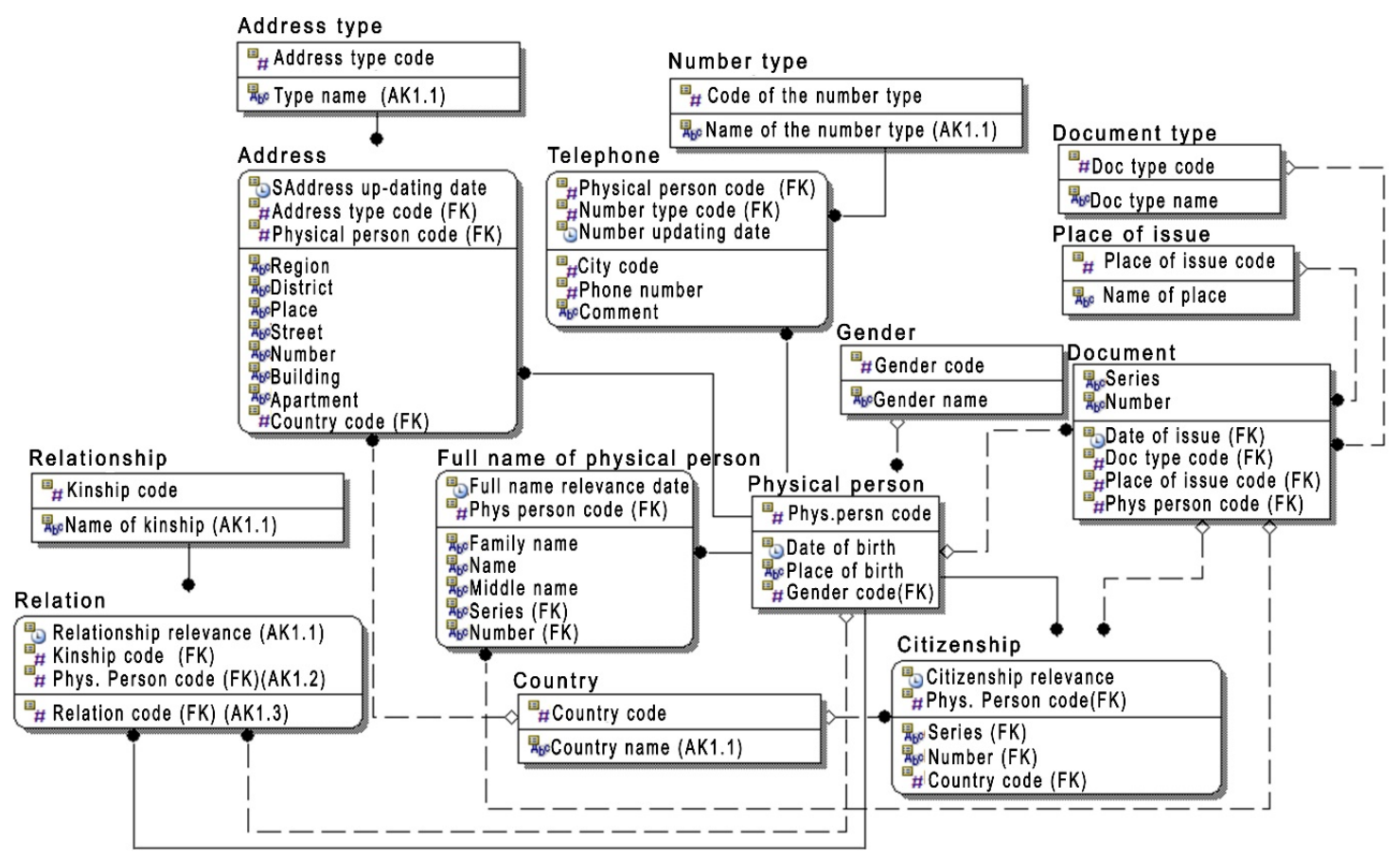

Fig.4. Application environment Physical persons of IDEF1X-model

The applicant's refusal of personal data processing, which results in his/her matriculation rejection, is a separate topic that lies beyond the scope of our present discussion.

\section{CONCLUSION}

At present all higher education institutions in Russia are required to export data as complex XML-packages to SFE\&UA system. After modifying the information model and system functioning algorithms and supplementing the system with printable applicant's application forms and matriculation (matriculation rejection) forms, SFE\&UA will be ready for use not only as Rosobrnadzor (Regulator in education sphere) supervision instrument, but also as the main information system uniting all educational institutions. It withdraws the need in continuous modification of in-house university information systems because of changes in SFE\&UA system DIFs or changes in admission regulations, and can result in significant financial savings. Besides it will reinforce supervisory functions of SFE\&UA system, as now the identity of the data stored in local information systems and SFE\&UA system cannot be verified. Unified forms of information presentation in Russian higher education institutions can increase the transparency of admission procedures in terms of relations with applicants, because today different institutions can differently interpret the requirements to the specification of the information published on official web-sites. 
When designing an IDEF1X-model of a centralized admission campaign in Russia the following principles should be observed: application form should clearly identify the desired higher education institution for each chosen specialty (field of study); the possibility of physical person data reduplication should be eliminated; the history of individual attribute values should be stored; and data access should be delimited in accordance with the current legislation.

The research was supported by the grants of the President of Russian Federation № MK226.2017.8 (Engineering) and № MK-5033.2016.8 (Engineering).

\section{REFERENCES}

1. Akbasheva G.A. Avtomatizirovannye sistemy «Abiturient»s «Student»kak chast' edinoj informacionnoj sredy vuza / G.A. Akbasheva, E.A. Akbasheva, Z.S. Lampezhev // Fundamental'nye issledovanija. - 2016. - № 4-3. - S. 465-469.

2. Pogromskaja T.A. Razrabotka v OMGU novoj informacionnoj sistemy prijoma v vuz // Matematicheskie struktury i modelirovanie. - 2016. - № 4 (40). - S. 116-121.

3. Pykhtin, A.I., Ovchinkin, O.V., Zeveleva, I.A. The algorithm for a single competition for admission to higher education programmes // International Journal of Applied Engineering Research, vol. 10 (7), c. 18417-18434.

4. Alexey I. Pykhtin, Oleg V. Ovchinkin, Natalia K. Zarubina. The Functional Model Of Centralized Admission Campaign To The Universities Of Russia // 4th International Multidisciplinary Scientific Conference on Social Sciences and Arts, SGEM 2017.

5. Epanchinceva O.L. Formirovanie edinogo konkursnogo prostranstva Omskogo regiona / O.L. Epanchinceva, T.A. Pogromskaja // Matematicheskie struktury i modelirovanie. - 2006. - № 16. - S. 5-10.

6. Min Zhu. College admissions in China: A mechanism design perspective. China Economic Review, 2014, vol. 30, pp. 618-631.

7. Kan M.V. Mezhvuzovskoe edinoe informacionnoe prostranstvo konkursnogo otbora abiturientov na primere Kirgizii // Sovremennye informacionnye tehnologii i IT-obrazovanie. - 2011. - № 7. - S. 357-368. 
How to cite this article:

Pykhtin A I, Ovchinkin O V. An information model of a centralized admission campaign in russian higher education institutions. J. Fundam. Appl. Sci., 2017, 9(2S), 1182-1190. 